\title{
Atendimento odontológico em pacientes soropositivo
}

\author{
Dental care in HIV positivo patients
}

Recebido: 29/09/2021 | Revisado: 03/10/2021 | Aceito: 05/10/2021 | Publicado: 12/10/2021

Victória Caroline Fernandes Precioso Moreno

Universidade Brasil, Brasil E-mail: Vickfernandesm@gmail.com

Camila Maria Medina

Universidade Brasil, Brasil

E-mail: Camilammedina0@gmail.com

Bruna Alves Demeis

Universidade Brasil, Brasil

E-mail: Brun1nha@icloud.com

José Lucas Martins

Universidade Brasil, Brasil

E-mail: José.lucas@universidadebrasil.edu.br

Paulo Roberto Gromatzky

Universidade Brasil, Brasil

E-mail: pgromatzky@gmail.com

Jane Sanchez

Centro Educacional Braz Cubas, Brasil

E-mail: janesanchez@terra.com.br

\begin{abstract}
Resumo
O vírus do HIV surgiu na década de 80 no Brasil, sendo considerado um problema de saúde pública. Os pacientes acabam sofrendo discriminação, preconceito e até injustiça social. Quando se instala no corpo, ele ataca o sistema imunológico provocando um declínio gradual da imunidade, o que provoca os primeiros achados clínicos da doença, aparecendo através das manifestações orais, como: Candidíase, Herpes, sarcoma de Kaposi, Leucoplasia, etc. Portanto o trabalho irá enfatizar o conhecimento e o comportamento da assistência odontológica de pacientes soropositivos. A referência estuda são de 1988 a 2021. Conclui - se que o cirurgião-dentista é responsável por identificar e diagnosticar os primeiros sinais da doença, a fim de estabelecer o tratamento para esse grupo de pacientes.
\end{abstract}

Palavras-chave: Biossegurança; HIV; Assistência odontológica.

\begin{abstract}
The HIV virus emerged in the 1980s in Brazil, being considered a public health problem. Patients end up suffering discrimination, prejudice and even social injustice. When installed in the body, it attacks the immune system causing a gradual decline in immunity, which causes the first clinical findings of the disease, appearing through oral manifestations, such as: Candidiasis, Herpes, Kaposi's sarcoma, Leukoplasia, etc. Therefore, the work will emphasize the knowledge and behavior of dental care for HIV-positive patients. The reference studies are from 1988 to 2021. It is concluded that the dentist is responsible for identifying and diagnosing the first signs of the disease, in order to establish the treatment for this group of patients.
\end{abstract}

Keywords: Biosafety; HIV; Dental care.

\section{Introdução}

A Síndrome da Imunodeficiência Humana (AIDS) é uma doença em que o patógeno (vírus) é transmitido por meio de relações sexuais, sangue, agulhas, seringas contaminadas e etc. (Belman, 2002).

Quando o agente infeccioso se instala no corpo, começa a atacar o sistema imunológico, resultando em um declínio gradual da imunidade, o que fará com que apareçam os primeiros sinais e sintomas da doença. (Cotran et al. 2000).

Devido à gravidade da doença, é responsabilidade dos profissionais da área de saúde se adaptarem às mudanças necessárias para cuidar do paciente com HIV. No entanto, há controvérsias quanto à possibilidade de admissão desses pacientes. Alguns autores relatam que medidas preventivas devem ser quanto ao atendimento odontológico, pesquisas mostram 
que é difícil para as pessoas que vivem com HIV obtê-lo. Na maioria das vezes, isso ocorre quando o profissional conhece a condição sorológica positiva da pessoa. (Discacciati; Vilaça, 2001).

Pelas consequências do ataque ao vírus aos portadores, o atendimento a esses pacientes é fundamental, pois os primeiros sinais da doença ocorrem por meio das manifestações orais. (Cavalcanti, 2015).

O estudo apresentado tem como objetivo compreender o conhecimento, atitudes, comportamentos, manifestações orais, biossegurança e ética do Vírus da Imunodeficiência Humana (HIV) por meio de uma revisão de literatura. Portanto, objetiva-se compreender o estágio atual do conhecimento sobre o assunto no contexto da odontologia e fornecer uma estrutura de referência com embasamento científico a esse respeito atribuído na hora do atendimento para que o risco de infecção seja nulo. (Gerbert 1988).

\section{Metodologia}

Este estudo utiliza como método a análise quantitativa descritiva, a partir de uma bibliografia que visa compreender o conhecimento e o comportamento relacionados ao vírus HIV, atitudes, desempenho oral, biossegurança e discriminação. (Pereira, et al. 2018).

Os critérios para os materiais incluídos neste estudo são os seguintes: artigos, Revistas ou livros que tratam do atendimento odontológico de pacientes soropositivos, escrito em português, o texto pode ser consultado em meio eletrônico, publicado no território nacional. Um total de 39 publicações foi analisado, incluindo livros, revistas, artigos que atenda aos critérios de inclusão e exclusão. Sites como Lilacs, Google Acadêmico, PubMed, Scielo (Scientific Eletronic Library Online), BDTD (Biblioteca digital brasileira de tese e dissertações) e revistas odontológicas foram utilizados como mecanismo de pesquisa.

\section{Revisão de Literatura}

\subsection{O Vírus da Imunodeficiência Humana (HIV)}

O HIV é um retrovírus da subfamília dos Lentiviridae, que se propaga em fluidos presentes no corpo humano, sendo sangue, sêmen, leite materno e secreções, atacando o sistema imunológico, responsável por defender o organismo. As células mais atingidas são os linfócitos T CD4+, onde o comprometimento inicia - se pela interação da glicoproteína. (Berguer E. A et al. 1999). Segundo Silva (2017) o HIV teve grandes proporções em 1980 e as pessoas em todo o mundo ficaram abaladas e assustadas com essa doença e por um bom tempo ela era chamada de "doença dos 5 H”, hemofilícos, homossexuais, haitianos, heroinômanos ( usuários de heroína injetável) e sex workes (acompanhante).

Existem dois principais tipos de HIV: De longe o mais prevalente o HIV1 e menos prevalente o HIV2. O virus tipo 1 e tipo 2 partilham muitas semelhanças, como seu arranjo gênico básico, modo de transmissão, vias de replicação intracelular e consequências clinicas: os dois resultam em AIDS. Porém o HIV - 2 tem uma menor transmissibilidade e menor progressão para AIDS, sendo mais comum na África Ocidental, enquanto o HIV - 1 se espalha por todo o mundo (Parham P. 2001).

No decorrer do processo de transcrição reversa, o DNA viral recém-formado fica associado ao complexo de transcrição reversa. Assim, a transcrição reversa pode introduzir erros no genoma viral a cada época de replicação, contribuindo para a alta diversidade genética do vírus (Hottiger M. ET al., 1996).

Pesquisas de Correa, Costa e Birman (1994) mostraram que a cavidade oral abriga um grande número de bactérias que se mantêm equilibradas. Infecções fúngicas e virais são as que mais afetam indivíduos com o Vírus da Imunodeficiência Humana (HIV), mas também outras doenças de origem bacteriana aparecem na cavidade oral, porém não tão claras. Certas lesões orais estão fortemente associadas á infecção pelo Vírus da Imunodeficiência Humana (HIV). A principal característica 
patológica do vírus da HIV é um declínio progressivo da imunidade, causando o surgimento de doenças oportunistas e neoplasias malignas (Echebarrpía \& Eguía, 2004).

Em 1996, uma nova classe de drogas de alta potência apareceu, o que aumenta a taxa de sobrevivência de pessoas infectadas pelo HIV / AIDS (Saldanha, 2009).

Os principais medicamentos usados por pacientes com o Vírus da Imunodeficiência Humana (HIV), são os antirretrovirais. Os chamados “coquetéis”, combinações dessas drogas que inibem a replicação do vírus em vários estágios. Outros medicamentos também estão disponíveis usados, entre outros: antidepressivos, ansiolíticos e medicamentos para tratamento de infecções (tuberculose, toxoplasmose, candidíase, pneumonia) (Felpel, 2000).

Com base em sua pesquisa, Felipe ET AL (2016) enfatizou que, além das formas de transmissão do Vírus da Imunodeficiência Humana (HIV) conhecidas, pode ocorrer também por transmissão acidental de trabalho afetando diretamente os profissionais da saúde, visto que eles fazem uso de materiais pontiagudos. Em um estudo de Arantes ET AL (2015), relatam que a biossegurança e a consciência ocupacional devem vir da graduação, já que um hábito de seguir protocolos deve ser estabelecido para reduzir o risco de infecção cruzada no ambiente odontológico.

Os profissionais da área de saúde devem estar bem informados sobre os processos da doença do vírus HIV / AIDS, seus sintomas na cavidade oral e como o vírus atua no corpo (Maruyama \& Ramos, 1996).

\subsection{Sinais e Sintomas}

Um ser humano pode ser soropositivo e não necessariamente ter um sistema imunológico comprometido com perda de linfócitos T, e pode viver muitos anos sem apresentar sintomas ou desenvolver AIDS. O organismo passa a produzir anticorpos. (Ministério da Saúde, 2013).

Neste tempo, o teste não detectou positivo porque ainda não há anticorpos, podendo variar entre 30/60 dias, embora a pessoa não tenha sido identificada como portadora do vírus da imunodeficiência humana (HIV) nesse período tele transportador (Buttò, S. ET al. 2010).

As maiores dos indivíduos infectados com o Vírus da Imunodeficiência Humana (HIV) desenvolveram cerca de um ou dois meses após a exposição ao vírus, e alguns sintomas são semelhantes aos de resfriado (Buttò, S. ET al. 2010).

Esta etapa, chamada de fase primária ou aguda, dura algumas semanas e é muito perigosa porque a infecção pode passar despercebida e a carga viral é muito alta nesse período, tornando o vírus fácil de espalhar. Após essa fase, os sintomas podem desaparecer espontaneamente por varios anos antes que o vírus seja diagnosticado. Indivíduos infectados podem apresentar os seguintes sintomas: Febre, mal estar, manchas vermelhas pelo corpo, aumento dos linfonodos ou ínguas, dores de cabeça, dores musculares, erupção cutânea, calafrios, dor de garganta, úlceras orais e genitais, dor nas articulações, sudorese noturna, diarreia e tosse (Hoenigl M. ET AL 2016).

\subsection{Diagnóstico}

A infecção pelo Vírus da Imunodeficiência Humana (HIV) pode ser confirmada por cultura de vírus ou detecção de antígenos e anticorpos para o HIV (Brasil, 2009). O teste rápido é recomendado principalmente para testes presenciais. Pode ser feito com uma amostra de sangue total obtida por punção venosa ou de polpa digital ou amostras de fluido oral. São aqueles que executam, leem e interpretam os resultados em no máximo 30 minutos. Além disso, são fáceis de implementar e não requerem estrutura de laboratório. (Brasil, 2009). O teste Elisa também é usado para detectar o Vírus. Este teste procura anticorpos produzidos pelo sistema imunológico para combater a infecção pelo HIV. (Brasil, 2000). 


\subsection{Tratamento}

Ainda não existe um tratamento capaz de eliminar o vírus, mas o tratamento com medicamentos antirretrovirais tem o objetivo de impedir a multiplicação do vírus no organismo levando o enfraquecimento do sistema imunológico. Atualmente existem 21 drogas apresentadas em 37 formas farmacêuticas. O tratamento com antirretrovirais deve ser iniciado assim que o diagnóstico é apresentado, antigamente tínhamos a contagem das células CD4+ após a diminuição da mesma começava o tratamento, sabendo que o melhor é iniciar antes mesmo disso e sim após o diagnóstico. (Brasil,2013)

Segundo MS (2006), os primeiros medicamentos antirretrovirais (ARV) surgiram na década de 1980, seu papel era inibir a reprodução do HIV no corpo, evitando assim o enfraquecimento do sistema imunológico. O desenvolvimento e a evolução dos medicamentos antirretrovirais para o tratamento do HIV transformaram o que antes era uma infecção fatal em uma doença crônica e controlável, embora ainda sem cura. Portanto, o uso regular de medicamentos antirretrovirais é essencial para garantir o controle da doença e prevenir a progressão para AIDS. A boa adesão à terapia antirretroviral (TARV) pode trazer enormes benefícios individuais, como aumento de energia e apetite, aumento da expectativa de vida e ausência de doenças oportunistas.

Desde 1996, o Brasil distribui gratuitamente todos os medicamentos antirretrovirais por meio do SUS (Sistema Único de Saúde). Desde 2013, o SUS garante o tratamento a todas as pessoas que vivem com HIV, independentemente da carga viral. Também se pode dizer que o tratamento pode ser usado como uma forma muito eficaz de prevenir as pessoas infectadas pelo HIV, evitando assim a transmissão sexual do HIV.(Brasil,2010).

Tem como objetivo o tratamento incluir e prolongar a qualidade de vida do paciente, reduzir a carga viral e reconstruir o sistema imunológico para que ele possa combater infecções oportunistas e reorganizar o corpo (FUNASA, 2002).

De acordo com Daniel e Parker (1991), com a ajuda de um coquetel anti-HIV, os portadores do HIV podem levar uma vida normal como portadores assintomáticos. Se tratados adequadamente, eles podem resistir a esta doença. Portanto, as pessoas que adquirem esta doença não podem ser condenadas à morte porque não há certeza de que isso acontecerá.

Para Gomez apud Ferreira et al. (2007), a introdução de medicamentos antirretrovirais no tratamento de controle da AIDS trouxe esperança e vitalidade a milhares de pessoas infectadas pelo Vírus da Imunodeficiência Humana (HIV). No entanto, esses mesmos medicamentos podem ter efeitos colaterais que podem afetar negativamente todos os aspectos da vida dos pacientes.

MS (2004) refere-se os efeitos colaterais como, toxicidade farmacológica ou reações adversas, ou seja, quaisquer reações inesperadas causadas por medicamentos. Eles podem ser leves e de curta duração, ou moderados e de longa duração; graves ou potencialmente fatais. Para reduzir ou eliminar alguns efeitos colaterais, médicos e pacientes estão tentando mudar o regime de medicação. Em qualquer caso, deve haver um sentido ao reduzir ou eliminar os efeitos colaterais dos medicamentos antivirais: o médico deve informar o paciente sobre a possível reação (a maioria das pessoas não apresenta nenhuma reação). Porém, o paciente é obrigado a comunicar ao médico todos os diferentes sintomas, mesmo os aparentemente simples, causados pelo tratamento, para que ele possa tomar providências necessárias.

\subsection{Atendimentos Odontológicos a pacientes soropositivos}

Independentemente da condição patológica do indivíduo, cada paciente deve receber atendimento da melhor forma dentro das diretrizes do Código de Ética Odontológica, Constituição Federal de 1988 e Normas de Biossegurança. O principal objetivo deste serviço é proporcionar aos pacientes uma melhor qualidade de vida. Por este motivo, o histórico médico do paciente deve sempre ser considerado para determinar os objetivos e meios de tratamento (Brasil, 1999).

Os profissionais da odontologia, assim como os profissionais da área de saúde, devem estar prontos para tratar pacientes com sintomas de infecção a qualquer momento. É considerada uma parte fundamentalmente importante do 
estabelecimento de confiança entre profissionais e pacientes (Brasil, 1999).

É importante ressaltar que os métodos de tratamento variam de acordo com as características médicas de cada paciente (Brasil, 1999).

\subsubsection{A rotina do tratamento odontológico}

Para pacientes com diagnóstico de HIV-AIDS, o dentista deve seguir alguns procedimentos. Uma delas é comprovar que o paciente recebeu atendimento médico especializado, depois, antes de iniciar o tratamento, deve seguir algumas das normas apontadas pela Coordenação Nacional de DST e Aids, que afirma:

1 Perguntar como está se sentindo; 2 Revisar a história médica; 3 Postergar procedimentos invasivos quando houver uma queixa médica não esclarecida; e 4 Fazer todas as anotações necessárias e planejar o procedimento antecipadamente evitando qualquer manipulação do prontuário até o final do tratamento (Brasil. 2000).

Porém, muitos pacientes consideram tais procedimentos desnecessários, contudo é importante preencher estes formulários, a análise do histórico médico também é muito importante, para que todo o processo de tratamento ocorra sem problemas e não represente riscos para a saúde dos pacientes com HIV / AIDS e dentistas (Brasil, 2000).

\subsubsection{Realização do exame clínico em pacientes soropositivos}

Depois de concluir o primeiro procedimento, o dentista pode iniciar os exames clínicos, incluindo exame extra e intra oral. O extra-oral são para analisar a pele, lábios, gânglios linfáticos, se há nódulos ou alguma alteração na área facial. Os exames intra-orais são para observar a mucosa oral e outras áreas (Brasil, 2000).

Feito a realização desses procedimentos, todos os relatórios ou observações devem ser registrados no prontuário do paciente para avaliação contínua, o paciente está sempre ciente dos procedimentos necessários a serem realizados, tais como novos sinais ou manifestações observados pelo dentista (Brasil, 2000).

\subsubsection{Tratamento preventivo}

Os métodos de prevenção são, sem dúvida, uma das melhores formas de prevenir doenças e problemas causados por patologias existentes. Para pacientes soropositivos, levando em consideração seu estado de imunodeficiência, os cuidados devem ser mais intensivos. Portanto, a higiene adequada é essencial para evitar complicações. A ausência de tratamento preventivo considerado comum em pacientes não portadores da doença, e é muitas vezes considerado grave em pacientes diagnosticado com a doença (Brasil, 2000).

Ainda no tratamento odontológico preventivo de pacientes soropositivos, as recomendações são as seguintes:

1 Controle a cada 3 meses; 2 Enxagues diários; e 3 Suplementação de flúor em aplicações tópicas, enxágues ou creme dental, particularmente para pacientes com xerostomia e aumento de incidência de cárie (Brasil, 2000).

Esses cuidados básicos são essenciais para que o quadro clínico do paciente não se agrave.

\subsubsection{Consulta de retorno}

O retorno à consulta com o dentista também traz algumas sugestões, é necessário reavaliar toda a história clínica do paciente, verificar se há alguma mudança no quadro clínico, se contém novos medicamentos e etc. Nesse caso, além da continuidade do tratamento, os cuidados com a higiene bucal devem ser reforçados (Brasil, 2000).

É importante dizer que não se pode negar qualquer tipo de atendimento odontológico ao portador do HIV-aids, 
considerado ilegal pela Constituição e pelo Código de Ética Odontológica (Brasil, 2000).

\subsection{Manifestações Bucais}

Após a infecção, o indivíduo permanecerá assintomático por vários meses/ anos, então os portadores podem não ter certeza de que possuem o vírus em seu corpo (Ramos Gomez, 2013).

Pacientes soropositivos imunossuprimidos podem apresentar manifestações orais, pois a principal característica patológica do vírus HIV é o declínio progressivo da imunidade celular e a subsequente ocorrência de infecções oportunistas e neoplasias malignas (Silva et al., 2017). A cavidade oral é o hospedeiro de muitas patologias, inclusive alterações causadas pela infecção do HIV (Teixeira et al., 2015)

De acordo com Lucena et al. (2016), algumas doenças são consideradas sinais clínicos confiáveis de nova infecção por HIV, progressão da doença e / ou falha do tratamento, visto que a TARV (terapia antirretroviral) reduz a carga viral do HIV e os linfócitos TCD4 + aumentam significativamente.

Na pesquisa de Felipe et al. (2016) e outros autores, as principais manifestações orais de pacientes infectados pelo HIV e suas características são:

\subsubsection{Infecção fúngica}

a. Candidíase Pseudomembranosa: È o tipo mais comum em indivíduos com HIV e o mais fácil de tratar, realizando a raspagem da área afetada, presente na mucosa jugal, palato, lábios e língua (Felipe et al. 2016).

\subsubsection{Bacterianas}

a. Periodontite Ulcerativa Necrosante Aguda (PUNA): É uma lesão de rápida progressão, o paciente apresenta sangramento espontâneo, como o nome sugere necrose, odor rançoso característico, perda severa do ligamento periodontal e osso alveolar (Felipe et al. 2016).

b. Gengivite Ulcerativa Necrosante Aguda (GUNA): As características são muito semelhantes às da PUNA, com diferença de edema e pseudomembrana (Felipe et al. 2016).

c. Eritema Gengival Linear: Ocorre na gengiva marginal a certa distância da gengiva livre e tem característica clínicas de eritema e edema (Felipe et al. 2016).

\subsubsection{Virais}

a. Herpes Simples: É uma das infecções virais que afetam os pacientes com HIV, caracterizada por um cacho de vesículas em forma de uva, que posteriormente se transformam em úlceras, que podem reaparecer (Felipe et al. 2016).

b. Leucoplasia Pilosa: Semelhante a Candidíase Hiperplásica localizada na borda externa da língua. Segundo Martins et al., (2018) analisaram 228 pacientes soropositivos em seu estudo e apontaram que as infecções oportunistas por Leucoplasia pilosa são as lesões mais comuns aparecendo em 23,7\% dos casos de avaliação (Felipe et al. 2016).

\subsubsection{Neoplásicas}

a. Sarcoma de Kaposi: Pode se manifestar como manchas vermelhas ou roxas únicas ou múltiplas e / ou nódulos tumorais vermelhos ou marrons (Felipe et al. 2016).

b. Linfoma não-Hodgkin: ocorre frequentemente nas gengivas, aumento de volume, indolor e pode estar localizado em qualquer parte da cavidade oral (Felipe et al. 2016). 


\subsection{Contaminação Cruzada}

Além dos próprios materiais e ferramentas, o ambiente odontológico também pode ter um grande potencial de contaminação. Uma variedade de bactérias respiratórias, orais e ambientais da pele pode ser detectada na placa de sedimentação da clínica odontológica. Esses microrganismos são considerados patógenos humanos e são resistentes a muitos antibióticos, portanto, é importante a realização de medidas eficazes de desinfecção de superfícies para minimizar a sobrevivência e disseminação desses microrganismos no ambiente clínico odontológico (Decraene et al., 2008).

\subsection{Biossegurança}

Com o surgimento dos primeiros casos confirmados de HIV, ocorreram preocupações com a adoção de métodos e medidas de biossegurança. O tema discutido passou a ser foco de atenção na prática médica e odontológica (Borges, 2014). Ja Oliveira e De Almeida (2015) também enfatizaram em suas pesquisas científicas que o dentista e sua equipe muitas vezes são suscetíveis a aerossóis e gotículas de canetas de alta rotação, que contaminam o ambiente e suas roupas. Segundo Silva Furlan et al. (2020) em suas pesquisas, mostra-se que os profissionais devem sempre atuar de acordo com os princípios da ética e da biossegurança para proteger o paciente, sua vida e o cuidado de sua equipe de trabalho.

“O tratamento odontológico de pacientes na fase ativa da doença deve ser adiado para evitar que o vírus infecte outras partes do corpo do paciente, e não representará risco para o dentista" (Oliveira \& de Almeida, 2015).

As infecções da corrente sanguínea ocorrem por meio do contato direto ou indireto com sangue e outros fluidos corporais. A saliva é um problema especial durante o tratamento dentário, porque geralmente está contaminada com sangue. Lembre-se de que, embora o sangue não seja visível na saliva, ele ainda pode estar presente. Instrumentos e equipamentos que não são totalmente desinfetados podem transmitir todas as doenças transmitidas pelo sangue (Borges, 2014).

\subsection{Função do Cirurgião-Dentista}

O papel do dentista é prevenir e diagnosticar precocemente a AIDS. Pacientes com essa doença são clientes potenciais de clínicas odontológicas porque as manifestações iniciais da AIDS geralmente são na boca. Portanto, os profissionais da odontologia desempenham um papel importante na promoção e adaptação à saúde bucal dos pacientes soropositivos, possibilitando-lhes uma melhor qualidade de vida (Greespan \& Greespan 1991).

O profissional da odontologia deve ter todo o conhecimento para cuidar do paciente soropositivo e principalmente na contaminação cruzada e transmissão de patógenos (Silva-Boghossian et al., 2020). E quando o dentista monitora frequentemente a condição bucal e o histórico médico do paciente, é mais fácil realizar um bom tratamento e prevenção (Raitz, 1997). O exame clínico e o diagnóstico devem ser registrados e descritos no prontuário do paciente (Rabelo, 2008).

\subsection{Discriminação, medo e falta de informação}

Atualmente, esses aspectos constituem alguns dos determinantes da não realização de procedimentos ou cuidados aos pacientes com HIV / AIDS. Porém, no cotidiano da prática profissional do cirurgião-dentista, é uma realidade atender pacientes soropositivos, principalmente considerando o grande número de pacientes portadores da doença em todo o mundo. Como os profissionais se recusam a cuidar de pessoas soropositivas, todos os aspectos são baseados na discriminação, medo de ser infectado acidentalmente durante a cirurgia e na falta de informação sobre a doença (DISCACCIATI JAC et al.,2009)

No entanto, deve-se ressaltar que o Código de Ética Profissional trata esse tipo de discriminação como violação, conforme o artigo 11 que diz: Trata-se de uma violação ética: I-discriminar o ser humano sob qualquer forma ou sob qualquer pretexto. Profissionais que violarem os preceitos deste Código de Ética serão punidos (DISCACCIATI JAC et al.,1999) e para Discacciati (1999), o saneamento ambiental é sem dúvida essencial para que os pacientes que não estão doentes se sintam 
seguros nos procedimentos de desinfecção e esterilização de materiais.

\section{Discussão}

Por meio de observações e análise Júnior et al. (2018), afirmaram que os dados estatísticos sobre a prevalência de pessoas infectadas pelo Vírus da Imunodeficiência Humana (HIV) variam de acordo com a população estudada, sendo que os homens são os mais prevalentes no brasil, no entanto, as mulheres são mais jovens quando estão infectadas. Ao contrário do conteúdo exposto, Melo et al. (2018) não concordou, porque de acordo com os resultados das suas pesquisas, a taxa de prevalência varia de acordo com o país ou continente a ser analisado, uma vez que suas pesquisas mostram que a maior taxa de prevalência do Vírus da Imunodeficiência Humana (HIV) está no continente africano, as mulheres jovens são as mais afetadas. Eles também relatam que, no brasil, embora as taxas de infecção em outras faixas etárias tenham diminuído, o número de pessoas com 50 anos ou mais aumentou.

O conhecimento sobre Hiv na área odontológica é considerado conhecimento básico, principalmente considerando a epidemia global de AIDS. Devem poder participar acadêmicos que desenvolvam processos de formação em cursos de graduação e dentistas em atividades clínicas, além de compreender o mecanismo de infecção (Silva \& Carvalho, 2018).

Com base em um estudo transversal qualitativo realizado por Maia et al. (2015), o Sistema Único de Saúde (SUS) oferece serviços de saúde universais e igualitários, considerando que os pacientes devem garantir a integridade dos serviços, independentemente de seus problemas de saúde, incluindo PVHA. Portanto, Lorosa et al. (2019) confirmaram esses princípios e mostraram que muitas pessoas que vivem com HIV/ AIDS não recebem atendimento odontológico adequado embora a higiene bucal seja muito importante, principalmente nos países em desenvolvimento.

\section{Considerações Finais}

Neste trabalho, procuro referências sobre o assunto que ajudem a compreender a complexidade da infecção pelo HIV. Vários pontos levam as pessoas a refletir sobre a vulnerabilidade dos infectados e como questões como pauperização, feminização, racismo, drogadição e juventude afetam a infecção.

Portanto, também é importante refletir, discutir e formular políticas públicas para reduzir / combater as diferentes vulnerabilidades que afetam as pessoas soropositivas. Além disso, deve ser estabelecida uma rede de apoio interativa para promover a adesão ao tratamento, permitindo o uso correto dos medicamentos e mudanças no estilo de vida para controle de vírus e doenças, facilitando o processo de adesão dos usuários.

A atitude dos profissionais em relação ao paciente durante o processo de tratamento é muito importante para a adesão. Além disso, enfatizou a necessidade dos profissionais da área da saúde e das políticas públicas compreenderem melhor o cotidiano das pessoas em tratamento. Portanto, as acusações sociais contra pessoas relacionadas podem ser evitadas.

\section{Referências}

Arantes, DC. et al. Biossegurança aplicada à Odontologia na Universidade Federal do Pará, Cidade de Belém, Estado do Pará, Brasil. Rev Pan-Amaz Saúde, Ananindeua, v. 6, n. 1, p. 11-18, mar. 2015.

Belman, AL. HIV-1 infection and AIDS. Neurol Clin. 2002;20(4):983-1011.

Berger, D.; Bernard, S.; Khzami, S-E.; Selmaou, S.; Carvalho, GS. Sex Education: Teachers' and Future Teachers' Conceptions and Social Representations: What relevance for Teachers' Training. In: XIII IOSTE Symposium- The Use of Science and Technology Education for Peace and Sustainable Development, Turkey, p. 21-26, 1999.

Brasil, Ministério da Saúde, Secretaria de Vigilância em Saúde, Programa Nacional de DST e AIDS. Direitos Humanos e HIV/AIDS: avanços e perspectivas para o enfrentamento da epidemia no Brasil. Brasília, 2008.

Brasil, Ministério da Saúde. Recomendações para terapia anti-retroviral em adultos e adolescentes infectados pelo HIV. 2004. http://www.aids.gov.br >. 
Brasil, Ministério da Saúde. Secretaria de Vigilância em Saúde. Departamento de DST, Aids e Hepatites Virais. Protocolo clínico e diretrizes terapêuticas para adultos vivendo com hiv/aids. Brasília, DF, 2013. <http://www.aids.gov.br/sites/default/files/anexos/publicacao/2013/55308/protocolo_13_3_20 14_pdf_28003.pdf>.

Brasil. Ministério da Saúde, Secretaria de Políticas de Saúde, Coordenação Nacional de DST e Aids. Controle de infecções e a prática odontológica em tempos de aids: manual de condutas - Brasília: Ministério da Saúde, 2000.

Brasil. Ministério da Saúde. Adesão ao tratamento an- tirretroviral no Brasil: coletânea de estudos do proje- to ATAR [internet]. Brasília, DF: Ministério da Saúde; 2010 http:// www.aids.gov.br/sites/default/files/atar-web.pdf

Brasil. Ministério da Saúde. Atenção à saúde do adulto - HIV/ AIDS. Belo Horizonte, 2006.

Brasil. Ministério da Saúde. Manual Técnico Para O Diagnóstico Da Infecção Pelo HIV. https://bvsms.saude.gov.br/bvs/publicacoes/ma nual_tecnico_diagnostico_infeccao_hiv.pdf.

Brasil. Ministério da Saúde. Secretaria de Políticas de Saúde. Coordenação Nacional DST e Aids. Infecção pelo HIV em adultos e adolescentes: recomendações para terapia antiretroviral. Brasília: Ministério da Saúde, 1999.

Buttò, S.; Suligoi, B.; Fanales-Belasio, E.; Raimondo, M. Laboratory diagnostics for HIV infection. Annali dell'Istituto superiore di sanità, [S.1.], v. 46, n. 1, p. 24-33, 2010.

Coelho RA, Facundo MKF, Nogueira AL, Sakano CRSB, Ribalta JCL, Baracat EC. Relação entre diagnóstico citopatológico de neoplasia intra-epitelial cervical e índices de células CD4+ e de carga viral em pacientes HIV-soropositivas. Rev Bras Ginecol Obstet. 2004;26(2):97-102.

Correa OCL, Costa CR, Birman EG. Manifestações bucais de doenças infecciosas em pacientes HIV positivos ou com AIDS. Parte III - Doenças bacterianas. Ver ABO Nac, v.2, n.3, p.187-190, 1994.

Cotran, RS, Kumar V, Collins T. Doenças da imunidade. In: Robbins SL. Patologia estrutural e funcional. 6. ed. Rio de Janeiro: Guanabara Koogan; 2000. Cap. 7, p.168-232.

Daniel, Herbert; Parker, Richard. AIDS: a terceira epidemia. São Paulo: Iglu, 1991.

Decraene, V. et al. Air-Borne Microbial Contamination of Surfaces in a UK Dental 19 Clinic. The Journal of General and Applied Microbiology, v.54, n.4, p.195-203, 2008.

Discacciati JAC, Vilaça EL. Atendimento odontológico ao portador do HIV: medo, preconceito e ética profissional. Rev Panam Salud Pública/Pan AmJ Public Health. 2009; 9(4):234-239.

Discacciati, J.A.C.; Vilaça, E.L. Atendimento odontológico ao portador do HIV: medo, preconceito e ética profissional. Revista Panamericana de Saúde Pública, 2001.

Felipe L.C.S. et al. Pacientes com HIV/AIDS na Odontologia e suas Manifestações Bucais. Journal of Orofacial Investigation., Campinas, vol. 3, n.1, p.53-62, 2016.

Felpel LP. Psicofarmacologia: antipsicóticos e antidepressivos. In: Yagiela JÁ, Neidle EA, DOWD FJ. Farmacologia e terapêutica para dentistas. Rio de Janeiro: Guanabara Koogan; 2000. Cap. 12, p.146-60.

Ferreira, Dayse Fróis; Lucas, Emanuel da Fonseca; Oleias, Francielli Daiana; Santos, Liliana Leite. Estudo quantitativo da não adesão ao tratamento dos clientes com HIV/AIDS atendidos no CRASE/GV. 2007. 72 P. TCC (graduação) - Universidade Vale do Rio Doce, Governador Valadares, 2007.

Gerbert B, Badner V, Maguirre B, Carlton R,Barnes D. Perceived personal risk: impact on dentists' infection control behaviors [abstract].J Dent Res1988;67(suppl):256.

Greenpan D \& Greenspan JS 1991. Management of the oral lesions of HIV infection. Journal Guia de vigilância epidemiológica / Fundação Nacional de Saúde. 5a ed.: FUNASA. Brasília, 2002. Volume 1. 482 p.

Hoenigl M, Green N, Camacho M, Gianella S, Mehta SR, Smith DM, et al. Sinais ou sintomas de infecção aguda por HIV em uma coorte submetida a triagem na comunidade. Emerg Infect Dis. 2016; 22 (3): 532-534. https://doi.org/10.3201/eid2203.151607

Júnior, J.L.A. et al. Perfil clínico e epidemiológico das alterações bucais em portadores do HIV. Arch Health Invest., vol. 7, n. 8, p. 339-343, junho, 2018

Lucena, N.T. et al. Conhecimento, atitudes e práticas dos estudantes de Odontologia com relação a pacientes HIV positivos. RFO UPF., Passo Fundo, vol.21, n.3, pp. 388- 394, Dez, 2016.

Melo, B.O. et al. Epidemiologia e aspectos imunopatológicos do vírus da imunodeficiência humana (HIV): revisão de literatura. Revista Ceuma Perspectivas., vol. 31, p. 86-100, 2018.

Oliveira, R. H. G.; DE Almeida, T. F. Riscos Biológicos em Odontologia. Revista Bahiana de Odontologia, v. 6, n. 1, p. 34-46, 2015.

Parham P. O sistema imune. Porto Alegre, RS: Artmed: 2000.

Pereira, A. S. et al. Metodologia da pesquisa científica. [free e-book]. Santa Maria/RS. Ed. UAB/NTE/UFSM, 2018.

Rabelo, R. G. (2008). Ocorrência de acidentes de trabalho e biossegurança em odontologia: a percepção dos estudantes de uma instituição de ensino superior. 
Ramos-Gomez, F.; Oral health considerations in HIV-infected children; 2013

Saldanha, JS, A. C. (2009). Grau de adesão ao tratamento com anti-retrovirais entre indivíduos HIV positivos atendidos no Hospital Universitário de Santa Maria. pp. 35(1):4-9-3.

Silva Furlan, S.M. F.; Lima, F. L.; Amorim, J.S. Atendimento odontológico ao paciente portador do HIV/AIDS. Revista Cathedral., v. 2, n. 3, p. 37-48, ago., 2020

Silva, E.A.A. Avaliação do perfil clínico e epidemiológico dos pacientes portadores do HIV, atendidos em unidade de emergência de alta complexidade. 2017. Dissertação (Mestrado em Gestão de Organizações de Saúde) - Faculdade de Medicina de Ribeirão Preto, Universidade de São Paulo, Ribeirão Preto, 2017.

Silva, L.V.R. et al. Tratamento das manifestações bucais de pacientes HIV-positivos: Revisão integrativa. RSC online., vol. 6, n. 3, p. $133-147$, set., 2017.

Silva-Boghossian, C.M. et al. Evaluation of oral care protocols practice by dentists in Rio de Janeiro towards HIV/AIDS individuals. BMC Oral Health. v.20, n.13, jan. 2020 .

Teixeira, H. et al. Manifestações orais em pacientes hiv soropositivos - Revisão de literatura. Jornada odontológica dos acadêmicos da católica - JOAC, v.1, n. 1,2015 . 